\title{
Study on miRNAs' Expression for the Invasion of Pituitary Adenomas
}

\author{
Guoqiang $\mathrm{YU}^{1,2^{*}}$, Hongyun WANG ${ }^{*}$, Shengyuan $\mathrm{YU}^{2}$, Chuzhong $\mathrm{LI}^{2}$, Jiwei BAI ${ }^{3}$, Songbai $\mathrm{GUI}^{3}$, Yazhuo ZHANG², \\ Peng $\mathrm{ZHAO}^{3}$ \\ ${ }^{1}$ Tsinghua University, Medical Center, Beijing, China \\ ${ }^{2}$ Capital Medical University, Beijing Neurosurgical Institute, Center of Brain Tumor, Beijing Institute for Brain Disorders, Beijing, China \\ ${ }^{3}$ Capital Medical University, Beijing Tiantan Hospital, Department of Neurosurgery, Beijing, China \\ *Guoqiang YU and Hongyun WANG contributed equally to this study.
}

\section{ABSTRACT}

AIM: To explore the possible invasive effect of four microRNAs (miRNAs) in invasive pituitary adenomas.

MATERIAL and METHODS: Based on our previous studies, several in silico algorithms, and relative literature, 30 Han Chinese patients with invasive pituitary adenomas and 30 with non-invasive pituitary adenomas were involved in this research. The proteins related to invasion underwent immunohistochemical staining, including basic fibroblast growth factor (FGF2), pituitary tumor transforming gene (PTTG), cyclin B1 (CCNB1), survivin, focal adhesion kinase (FAK), and microvessel density (MVD). To validate the effect of miRNAs, miR-24, miR-93, miR-126, and miR-34a were chosen as possible targets for the aforementioned proteins with four in silico algorithms. All miRNAs tests were performed using quantitative real-time polymerase chain reaction (qPCR). The expression levels of proteins and miRNAs associated with tumors' invasiveness were analyzed.

RESULTS: In our study, FGF2, FAK, PTTG, CCNB1, and MVD were overexpressed in the invasive group compared with the noninvasive group, while an increase in the expression of survivin in the invasive group did not achieve statistical significance. This paper reviewed the literature, and four miRNAs involving invasion were selected for study: miR-24, miR-34a, miR-93, and miR-126. Under-expression of miR-24, miR-34a, and miR-93 was significant in the invasive group, while a decrease of miR-126 expression in the invasive group did not achieve statistical significance.

CONCLUSION: FGF2, PTTG, CCNB1, survivin, FAK, and MVD proteins of pituitary adenoma showed strong expression in invasive tumors. Furthermore, miR-24, miR-93, miR-34a, and miR-126 were under-expressed in invasive Pituitary adenomas compared with non-invasive ones. The results indicated some relationship between the miRNA and protein expression during the pituitary invasion process.

KEYWORDS: Invasive, microRNA, Non-invasive, Pituitary adenoma

\section{INTRODUCTION}

$\mathrm{P}$ ituitary adenomas are considered benign tumors. However, $45-55 \%$ of them are reported as invading structures such as the sphenoid, cavernous sinus, or dura mater (24). While such invasive pituitary adenomas are associated with substantial morbidity and mortality, the prediction of invasive or malignant behavior in pituitary adenomas remains challenging. Research has been conducted to study the mechanisms involved in the invasion of pituitary adenomas, but remains unknown.

From our single neurosurgical unit, previous studies suggested that basic fibroblast growth factor (FGF2), pituitary tumor 
transforming gene (PTTG), and cyclin B1 (CCNB1) protein were involved in the pathogenesis of pituitary adenomas of Han Chinese patients $(16,46)$. However, the possible roles of these proteins in the invasiveness of pituitary adenomas in Han Chinese patients remain unclear. Moreover, FGF2 functions mostly promote tumor angiogenesis; microvessel density (MVD) is related with angiogenesis if it is expressed differentially in invasive pituitary adenomas $(12,25,45)$. In addition, survivin and focal adhesion kinase (FAK) are known to interact with FGF2 $(30,33,37)$, and promote tumor angiogenesis $(32,37)$.

In recent years, microRNAs (miRNAs) have been found to play important roles in tumor pathogenesis and invasion, and researchers have demonstrated abnormal expression of several miRNAs involved in the development of pituitary adenomas, as reviewed by Sivapragasam et al.(31). However, there are few studies of miRNAs focusing on the invasion of pituitary adenomas.

To validate the effect of miRNAs, we chose miRNAs to be the possible targets of the proteins with four in silico algorithms (TarBase, miRTarBase, miRanda, TargetScan). The criteria for the relationship between miRNA and proteins were set as follows: 1) being obtained by at least three algorithms, or being testified by experiments to target or directly inhibit one of the studied proteins; 2) and being involved in the invasiveness of other tumors and involved in the pathogenesis of pituitary adenomas, but involvement with pituitary adenoma invasiveness being unclear. With these criteria we selected four miRNAs to study: miR-24, miR-34a, miR-93, and miR126. The purpose of the present study was to determine whether these miRNAs were associated with pituitary adenoma invasion, and to present results that could possibly improve the understanding of pituitary adenoma invasion.

\section{MATERIAL and METHODS}

\section{Patients' Material}

This study was approved by the Ethical Review Board of Beijing Neurosurgical Institute and Beijing Tiantan Hospital, Capital Medical University. Informed consent was obtained from all enrolled subjects, and the study was carried out in full compliance with all principles of the Helsinki Declaration.

We reviewed patients who were diagnosed as sporadic pituitary adenoma and underwent surgery (transsphenoidal surgery or craniotomy) from March 2008 to May 2015 at the Neurosurgical Department of Beijing Neurosurgical Institute and Beijing Tiantan Hospital. We randomly selected 30 invasive pituitary adenoma cases and 30 non-invasive for this research. For each patient, tumor samples were stored in liquid nitrogen soon after surgical removal.

Based on preoperative magnetic resonance imaging (MRI) images, intraoperative records, and pathological results, the following criteria were used to identify tumor invasiveness by a group of specialists of neurosurgeons, radiologists, and pathologists: 1) grade four according to the Knosp grading system or Hardy classification (17), 2) grade two and three according to the Knosp grading system combined with any type of extrasellar extension (eroding bone tissue of sellar clivus, or invading into unilateral/bilateral cavernous sinus) from operative records, and/or with dural invasion on the pathological slides.

\section{Immunohistochemical Staining}

Pituitary adenoma samples were embedded in optimal cutting temperature compound (Sakura Finetek, Torrance, CA, USA), and $8 \mu \mathrm{m}$ thin sections prepared using a cryostat (Shandon Cryotome E, Thermo Fisher, MA, USA) were put on adhering microscopes slides (Citoglas, Jiangsu, CHN). They were then infiltrated in cold acetone for 10 minutes and washed three times in phosphate buffer saline (PBS) for 5 minutes. Then, sections were treated with $0.3 \%$ Triton X-100 for 30 minutes. Next, they were washed three times in PBS for 5 minutes, incubated for 10 minutes with $0.03 \%$ hydrogen peroxidase to block endogenous peroxidase activity, and then washed another three times in PBS for 5 minutes. All specimens were incubated overnight at $4^{\circ} \mathrm{C}$ with primary antibodies: antiFGF2, anti MVD, anti-survivin, anti-FAK, anti-PTTG, and antiCCNB1. Samples were then rinsed three times in PBS for 5 minutes, incubated for 15 minutes with secondary antibody, and washed another three times in PBS for 5 minutes. Sections were counterstained with hematoxylin, dehydrated, and mounted.

The numbers of positive immunostaining were counted at $\times 40$ in three separate fields by microscope. Evaluation of the sections was performed three times and was based on estimated values for staining intensity (SI) (0: no staining; $1+$ : weak; 2+: moderate; $3+$ : strong; and 4+: very strong staining) and percentage of positive staining (PP) in tissue sections (0: no positive cells; 1 : $1-25 \%$; 2 : $26-50 \%$; 3 : $51-75 \%$; and $4: 76-100 \%$ positive cells). The immunohistochemical score value was then calculated by multiplication of SI and PP. All immunohistochemical results were reviewed by a neuropathologist who was blinded to the clinical parameters.

\section{Method for Choosing Candidate Relative miRNAs with Invasion}

We used four different software to search for the miRNAs targeting 1 or more of the selected protein markers: TarBase v7.0 (http://diana.imis.athena-innovation.gr/DianaTools/index. php?r=tarbase/index) (34), miRTarBase 6.1 (http://miRTarBase. mbc.nctu.edu.tw/) (8), miRanda (http://www.microrna.org/ microrna/home.do) (1), and TargetScan 7.0 (http://www. targetscan.org/vert_70/) (19). The criteria are described in the introduction. We chose miR-24, miR-34a, miR-93, and miR126 for study using this software. We then used Cytoscape 3.4.0 to construct a relationship network between candidate miRNAs with invasion and corresponding proteins.

miRNA Expression in Pituitary Tissues and Quantitative Real-time Polymerase Chain Reaction (qPCR)

qPCR was performed to further verify the correlation of selected miRNA in this group of patients. Total miRNA was extracted and purified using the isoRNA for small RNA (Takara, Dalian, $\mathrm{CHN}$ ) following the manufacturer's instructions. An 
Agilent Bioanalyzer 2100 (Agilent Technologies, Santa Clara, CA) was used to obtain an RNA integrity number (RIN) (29), and inspect RNA integration. Only those samples that showed no degradation ( $\mathrm{RIN} \geq 7.0$ and $28 \mathrm{~S} / 18 \mathrm{~S} \geq 0.7$ ) were used to generate labeled targets. qPCR was performed with an $\mathrm{ABI}$ 7500 Fast Real-Time PCR System using SYBR PrimeScript miRNA RT-PCR Kit (Takara, Dalian, CHN) based on the kit's protocol. A $20 \mu \mathrm{L}$ reaction system containing $2 \times$ SYBR Premix Ex Taqll $(10 \mu \mathrm{L}), 10 \mu \mathrm{M}$ each of the forward and uni-miR qPCR Primer (0.8 $\mu \mathrm{L}$ each), cDNA template $(2 \mu \mathrm{L})$, and ddH2O (8 $\mu \mathrm{L})$, was set up. The U6 shRNA was selected as the reference gene. miRNA expression of each target gene was determined using the value of the cycle threshold. The relative expression was calculated using the $2^{-\triangle \triangle C T}$ method after comparison with U6 (26). The primer sequences of U6 and the four selected target genes are shown in Figure 1.

\section{Statistical Analysis}

We used SPSS 23.0 statistical software (SPSS Inc., IL, USA) for statistical evaluation. Measurement data were presented as mean \pm standard error of the mean (SEM) and analyzed using independent two-sample $t$ tests or Mann-Whitney $U$ tests (based on the distribution of data). Differences were considered significant at $\mathrm{p} \leq 0.05$.

\section{RESULTS}

Analysis Protein Expression of FGF2, PTTG, CCNB1, FAK, Survivin, and MVD by Immunohistochemistry

All selected proteins were expressed in pituitary adenomas.
The immunohistochemical score values are shown in Figure 2. Staining intensity of FGF2, PTTG, CCNB1, survivin, FAK, and MVD was weak in non-invasive tumors, while very strong expression was found in invasive tumors (Figure 3AE). Although survivin positive staining was mainly observed in invasive pituitary adenomas, there was no significant difference of immunohistochemical score values between invasive tumors and non-invasive tumors (Figure 3 C1-2; Figure 2, $p=0.28$ ).

\section{Candidate miRNAs With Invasion}

As described above, we chose possible targets of the protein markers FGF2, MVD, PTTG, CCNB1, survivin, and FAK with four in silico algorithms. Then, according to associated literature and our previous experiments, four miRNAs fitting our criteria were selected for study including miR-24, miR$34 a$, miR-93, and miR-126. The relationship between the selected miRNAs and the proteins is illustrated with Figure 1, which was constructed by Cytoscape 3.4.0.

Analysis of miR-24, miR-34a, miR-93, and miR-126 expression by qPCR

Total RNA was isolated from invasive and non-invasive tumor samples, and qPCR was performed using specific primers as described above. The differential expression patterns of miR24, miR-34a, miR-93, and miR-126 are shown in Figure 4A-D. Expression of miR-24, miR-34a, and miR-93 were significantly decreased in invasive pituitary adenomas compared with noninvasive pituitary adenomas (Figure $4 \mathrm{~A}-\mathrm{C} ; \mathrm{p}=0.014, \mathrm{p}=0.018$, $p=0.013$, respectively). Although expression of $\mathrm{miR}-126$ in

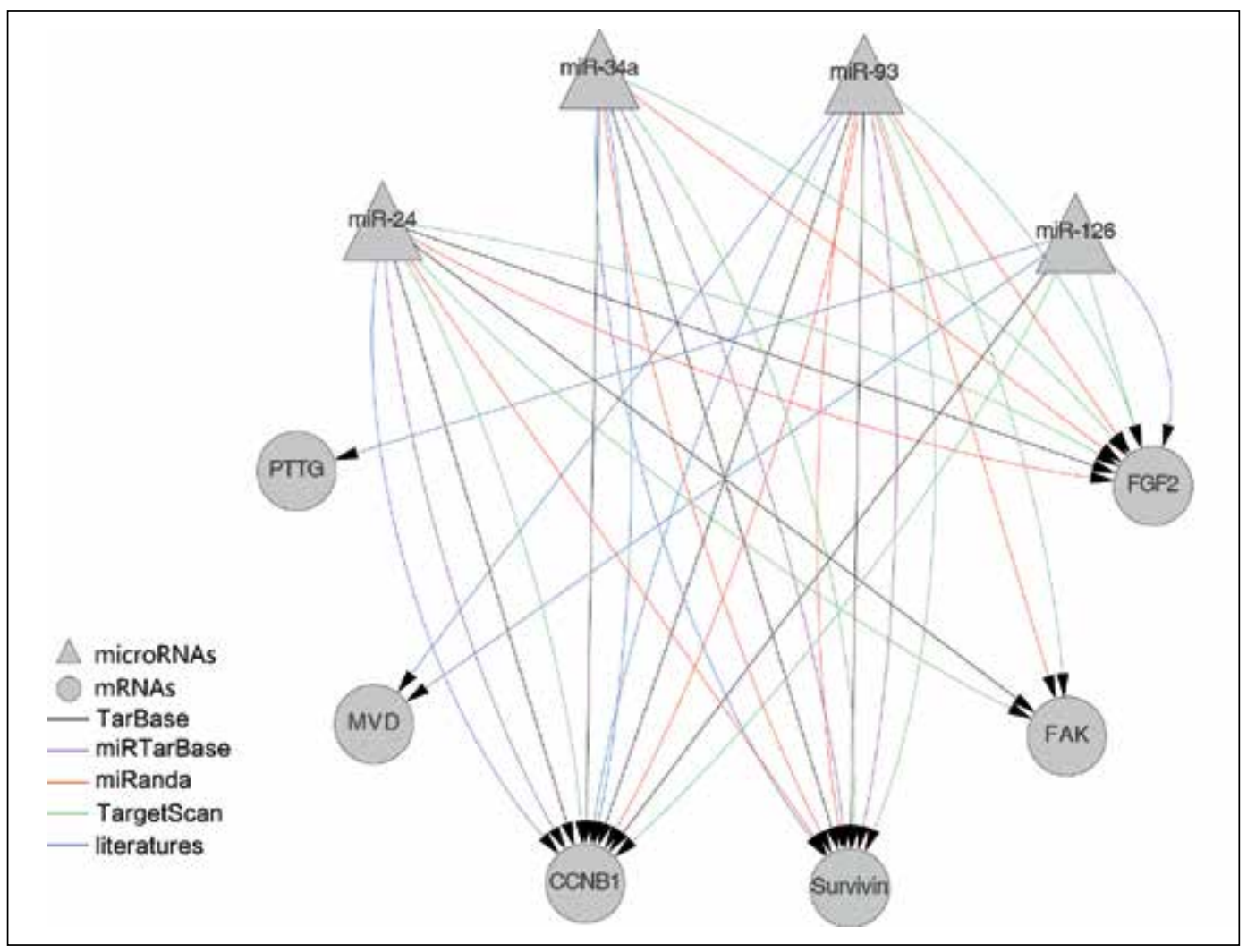

Figure 1: Schematic diagram illustrating the relationship of candidate miRNAs and protein markers. The black, purple, red, and green lines refer to targeting prediction by TarBase, miRTarBase, miRanda, and TargetScan, respectively. The blue lines refer to targeting or a direct inhibition relationship testified by experiments from previous report. 


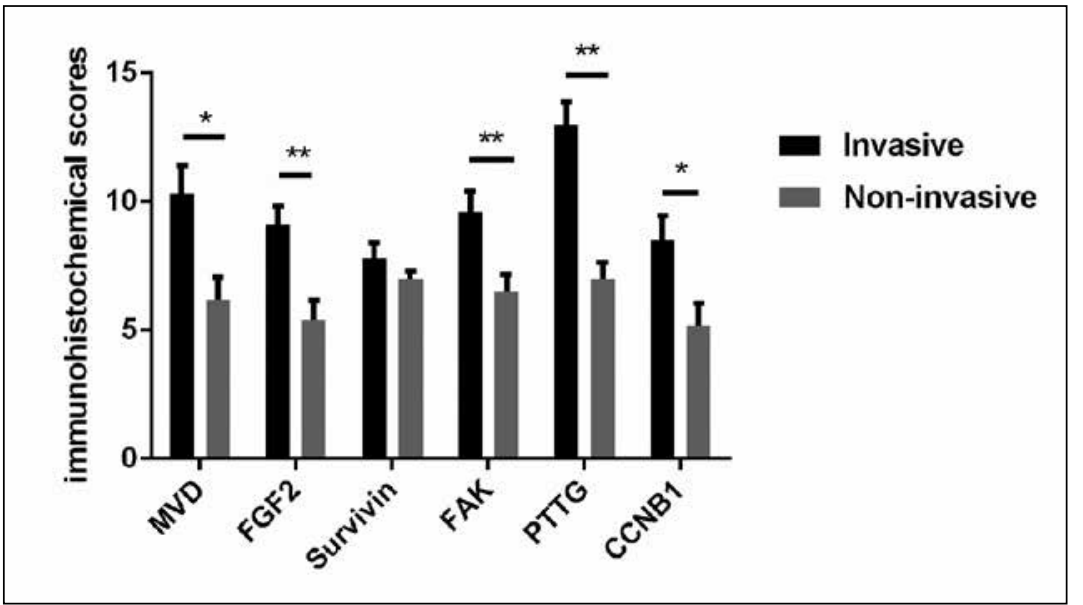

Figure 2: Immunohistochemical score profiles in invasive and non-invasive Pituitary adenomas. Each point with bars shows mean \pm SEM. * $p$ $<0.05,{ }^{\star *} \mathrm{p}<0.01$.
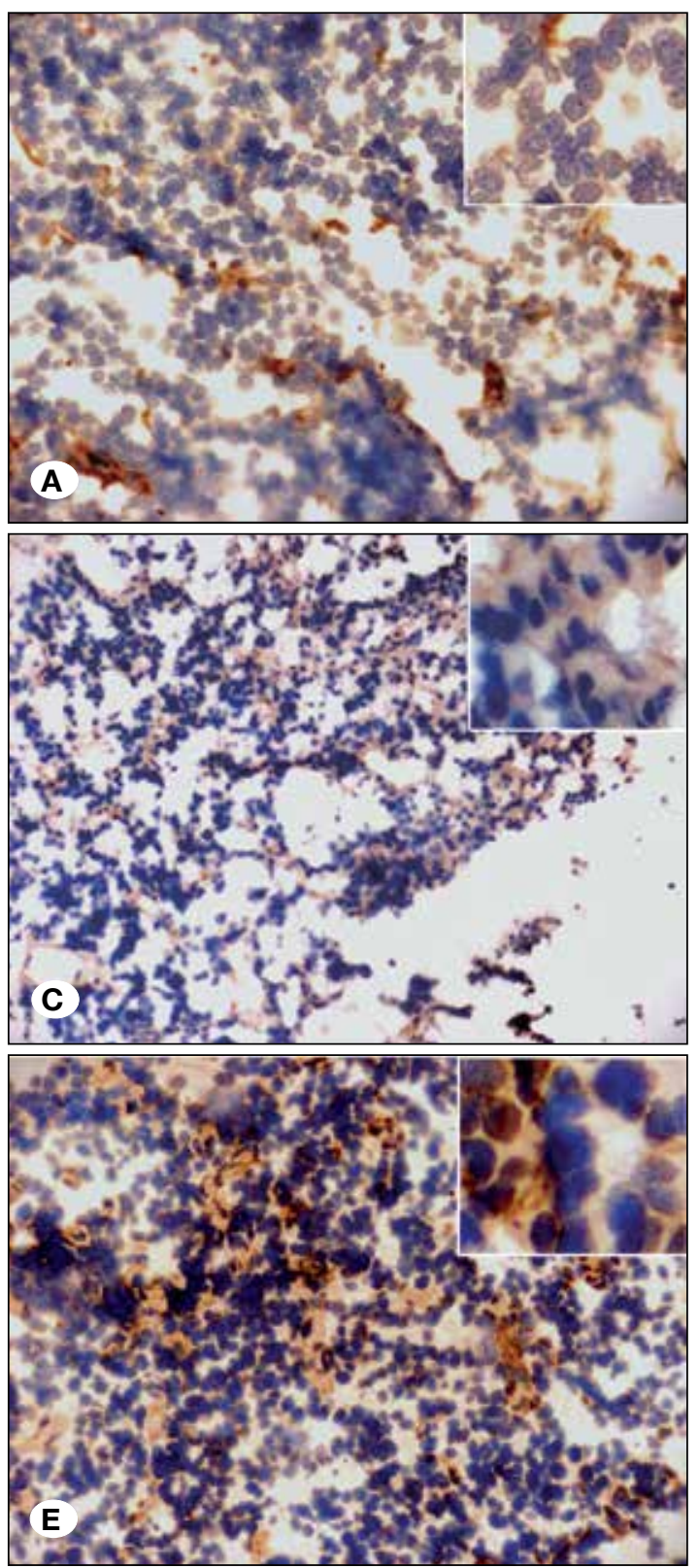
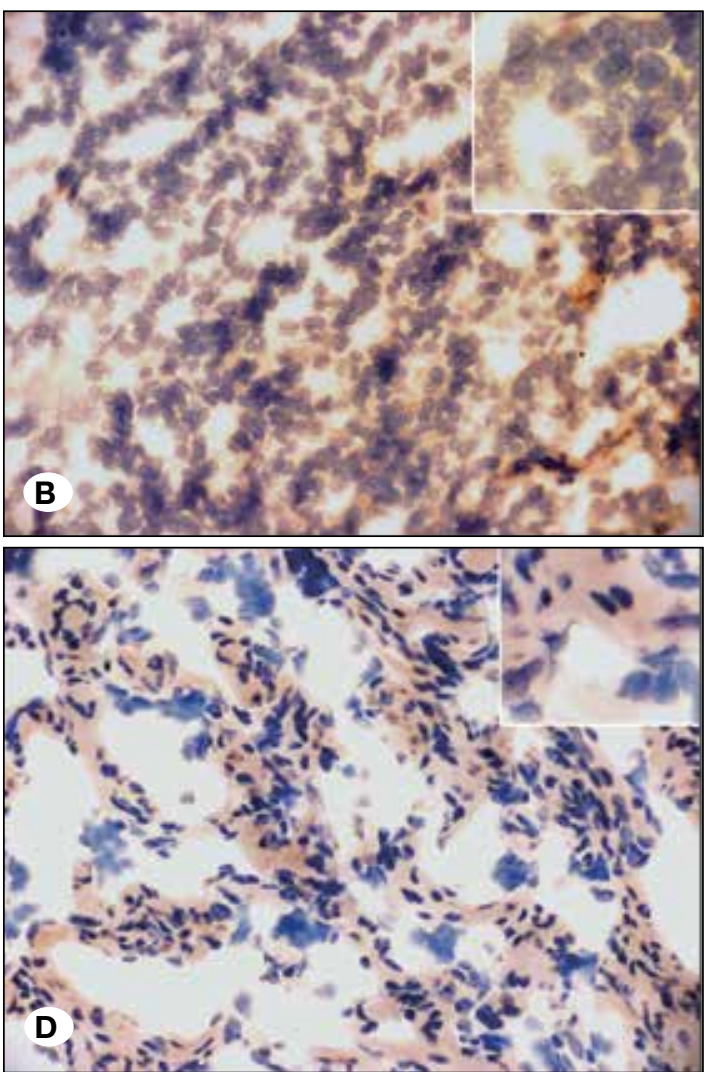

Figure 3: Immunohistochemical analysis of PTTG, FAK, FGF2, MVD, and CCNB1 in invasive pituitary adenoma. Typical positive immunostainings for A) PTTG, B) FAK, C) bFGF, D) MVD, and E) CCNB1 are shown in brown color. (magnification 1: $\times 20$; magnification 2: $\times 40$ ). 
invasive pituitary tumors was also decreased compared with non-invasive pituitary adenomas, the difference did not achieve statistical significance (Figure 4D, $p=0.179$ ).

\section{DISCUSSION}

The classification of invasive pituitary adenoma is assessed by the value and significance from Knosp and Hardy classification. However, there are still no possible biomarkers to distinguish invasive tumors from non-invasive tumors. Proteins related to the pituitary tumor invasion mechanism have been involved in many studies, and herein MVD, FGF2, PTTG, CCNB1, survivin, and FAK were considered as potential proteins with invasion $(16,46)$. The expression of these proteins with immunohistochemical staining in Han Chinese patients was examined from our previous studies $(16,46)$. There was a significant difference between the invasive group and noninvasive group in the expression levels of each protein, except for survivin. Survivin protein expression was also higher in the invasive group; however, the two groups did not show statistical difference in our study. Results indicated that these proteins are possibly associated with pituitary adenoma invasion $(14,16,21,27,35,36)$.

miRNAs have been found to play important roles in tumor pathogenesis and invasion, and researchers have demonstrated abnormal expression of several miRNAs involved in the development of pituitary adenomas $(14,16,21,27,35,36)$. In our research, four miRNAs (miR-24, miR-93, miR-126, and miR-34a) were chosen based on experiments, in silico software and the literature. We examined the expression of protein markers and these four miRNAs in invasive pituitary adenomas compared with non-invasive pituitary adenomas (Figure 1). Although the pathogenic relationships between these miRNAs and the proteins (FGF2, PTTG, CCNB1, FAK, survivin, and MVD) had been testified in other tumors, it is unclear whether these targeting or inhibitory relationships exist in pituitary adenomas, especially for invasion.

Recently, several reports suggested that miR-24 plays important roles in tumor angiogenesis and pituitary adenoma growth (31). Furthermore, miR-24-1 was found to be downregulated in pituitary adenomas compared with normal pituitaries (2), and miR-24-2 was downregulated in non-functional pituitary adenoma while upregulated in somatotrophinomas and prolactinomas (2). However, neither of these studies covered the invasion mechanism of pituitary adenoma. In other studies, miR-24 was shown to different roles. It suppressed invasiveness in gastric cancer cells (20), and lacrimal adenoid cystic cancer cells (44), whilst promoted invasiveness in cholangiocarcinoma (11), and bladder cancer (42). The current study showed that miR-24 was downregulated in invasive pituitary adenomas compared with the non-invasive group, which possibly indicated its negative role in pituitary adenoma invasion.

Butz et al. reported miR-93 overexpressed in non-functional pituitary adenoma and somatotrophinomas compared with normal pituitaries (3), and Wu et al. found that miR-93 and

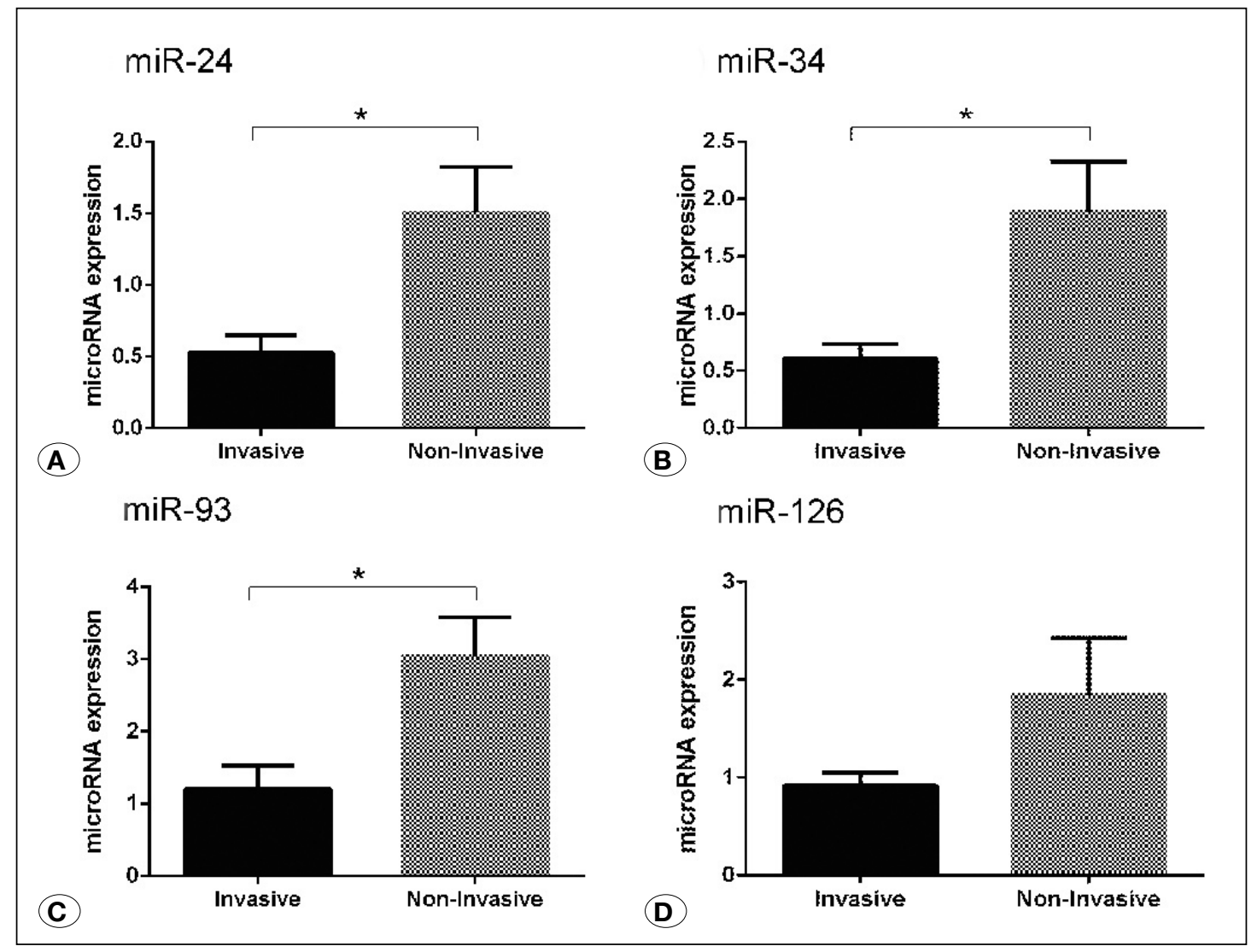

Figure 4: Gene expression profiles of 4 miRNAs in invasive and noninvasive Pituitary adenomas. Transcript copy numbers per microgram miRNAs of A) miR-24, B) miR$34 a$, C) miR-93, and D) miR-126, were determined by realtime quantitative RTPCR. Each point with bars shows mean \pm SEM. ${ }^{*} p<0.05$. 
other miRNAs, including miR-126, were upregulated in bromocriptine-resistant prolactinomas (38). In these reports, miR-93 was demonstrated to promote cell proliferation and tumor development by targeting p21, a cyclin kinase inhibitor $(3,38)$. Thus, miR-93 may be considered as an oncogene of tumor genesis. It also had been found to promote invasiveness in glioma (6), and endometrial growth in carcinoma cells (7). Additionally, Yang et al. studied early relapse of colorectal cancer (39), and found that miR-93 had anti-oncogenic effects by inhibiting cell proliferation, migration, and tumor growth; however, they did not find any effect in tumor invasion. They also confirmed that in addition to $\mathrm{p} 21$ and vascular endothelial growth factor (VEGF), CCNB1 were directly targeted by miR93. Since CCNB1 was reported to be related with pituitary adenoma invasion (27), we wondered whether miR-93 was involved with pituitary adenoma invasion. Our results showed decreased expression in invasive pituitary adenomas, possibly indicating an inhibitive function of miR-93 on invasion. This result was consistent with those by Yang et al. (39), and suggested that miR-93 has a relationship with tumor proliferation.

Denes et al. reported no difference of miR-34a expression between pituitary adenomas and normal pituitaries, nor between invasive tumors and non-invasive tumors (10). Furthermore, D'Angelo et al. found that miR-34b decreased in somatotrophinomas compared with normal pituitaries (9), and overexpression of miR-34b suppressed tumor cell proliferation in in vitro targeting oncogenes HMGA1 and HMGA2. Thus, D'Angelo's results possibly indicated an anti-oncogene effect of miR-34 in pituitary adenoma. Zhang et al. found that miR$34 \mathrm{a}$ inhibited migration and invasion in colorectal cancer, as well as the phosphorylation of FAK (43). Additionally, miR34 a suppressed tumor invasion partly through inhibiting survivin expression in gastric cancer (4), and in head and neck squamous cell carcinoma (18). Here, our research demonstrated that miR-34a was downregulated significantly in the invasive group compared with the non-invasive group. This finding was inconsistent with Denes' report, probably because of the differences in sample subtypes selected in our study.

Mao et al. found that miR-126 was downregulated in growth hormone $(\mathrm{GH})$-secreting pituitary adenomas compared with normal pituitaries (23). Furthermore, miR-126 targeted PTTG1 (23), which is important in pituitary adenoma pathogenesis and involved in many processes including invasion (28). miR126 was also found to be downregulated in gastric cancer associated with local invasion $(5,13)$; and the target gene of expression inhibited tumor growth partly through downregulating VEGF and MVD (5). miR-126 was significantly decreased in oral squamous cell carcinoma with inhibited cell proliferation and invasion, and FGF2 and VEGF were downregulated (40). Huang et al. found that miR-126 was downregulated and showed inhibition effects on invasion in colon cancer (15). All these above reports indicated that miR-126 acts as a tumor suppressor and may also inhibit invasion in pituitary adenomas. Furthermore, Yang's research revealed that miR126 promoted tumor invasiveness in gastric cancer (41), while Li's research found that miR-126 was overexpressed in acute myeloid leukemia and enhanced tumor cell proliferation (22). The current study showed a decreased expression of miR-126 in invasive pituitary adenomas compared with non-invasive pituitary adenomas, but the difference between the two groups did not achieve statistical significance; note that these results were different from those of the other three miRNAs. Our results contradicted Mao's research (23), probably due to the number of tumor samples used in the present study. Although miR-126's involvement in pituitary adenoma invasion is unclear, more study will be further performed regarding the invasion mechanism.

Our research demonstrated the overexpression protein of FGF2, FAK, PTTG, CCNB1, surviving, and MVD in invasive pituitary adenomas. Although we cannot clarify these relationships in an actual invasion process, these results are of importance because miR-24, miR-93, and miR34a were under-expressed in invasive pituitary adenomas: since these miRNAs have been found in pathogenesis in multiple tumors, results indicated new mechanisms of pituitary adenoma invasion and more effective therapy targets.

\section{CONCLUSION}

FGF2, PTTG, CCNB1, survivin, FAK, and MVD proteins of pituitary adenoma were overexpressed in invasive tumors, while miR-24, miR-93, miR-34a, and miR-126 were underexpressed in invasive pituitary adenomas compared with non-invasive pituitary adenomas. Therefore, there is some relationship between the miRNA and protein expression during pituitary invasion.

\section{ACKNOWLEDGMENT}

This work was supported by grants from the Beijing Natural Science Foundation (7162034) and Basic Research and Clinical Study Project of Capital Medical University (15JL54).

\section{- REFERENCES}

1. Betel D, Wilson M, Gabow A, Marks DS, Sander C: The microRNA.org resource: Targets and expression. Nucleic Acids Res 36: D149-D153, 2007

2. Bottoni A, Zatelli MC, Ferracin M, Tagliati F, Piccin D, Vignali C, Calin GA, Negrini M, Croce CM, Degli Uberti EC: Identification of differentially expressed microRNAs by microarray: A possible role for microRNA genes in pituitary adenomas. J Cell Physiol 210: 370-377, 2007

3. Butz H, Liko I, Czirjak S, Igaz P, Khan MM, Zivkovic V, Balint K, Korbonits M, Racz K, Patocs A: Down-regulation of Wee1 kinase by a specific subset of microRNA in human sporadic pituitary adenomas. J Clin Endocrinol Metab 95: E181-191, 2010

4. Cao W, Fan R, Wang L, Cheng S, Li H, Jiang J, Geng M, Jin Y, Wu Y: Expression and regulatory function of miRNA-34a in targeting survivin in gastric cancer cells. Tumour Biol 34: 963971,2013

5. Chen H, Li L, Wang S, Lei Y, Ge Q, Lv N, Zhou X, Chen C: Reduced miR-126 expression facilitates angiogenesis of gastric cancer through its regulation on VEGF-A. Oncotarget 5: 11873-11885, 2014 
6. Chen R, Liu H, Cheng Q, Jiang B, Peng R, Zou Q, Yang W, Yang X, Wu X, Chen Z: MicroRNA-93 promotes the malignant phenotypes of human glioma cells and induces their chemoresistance to temozolomide. Biol Open 5:669-677, 2016

7. Chen $S$, Chen X, Sun KX, Xiu YL, Liu BL, Feng MX, Sang XB, Zhao Y: MicroRNA-93 promotes epithelial-mesenchymal transition of endometrial carcinoma cells. PLoS One 11: e0165776, 2016

8. Chou $\mathrm{CH}$, Chang NW, Shrestha S, Hsu SD, Lin YL, Lee WH, Yang CD, Hong HC, Wei TY, Tu SJ, Tsai TR, Ho SY, Jian TY, Wu HY, Chen PR, Lin NC, Huang HT, Yang TL, Pai CY, Tai CS, Chen WL, Huang CY, Liu CC, Weng SL, Liao KW, Hsu WL, Huang HD: miRTarBase 2016: Updates to the experimentally validated miRNA-target interactions database. Nucleic Acids Res 44: D239-D247, 2016

9. D'Angelo D, Palmieri D, Mussnich $P$, Roche $M$, Wierinckx A, Raverot G, Fedele M, Croce CM, Trouillas J, Fusco A: Altered microRNA expression profile in human pituitary $\mathrm{GH}$ adenomas: Down-regulation of miRNA targeting HMGA1, HMGA2, and E2F1. J Clin Endocrinol Metab 97: E1128-1138, 2012

10. Denes J, Kasuki L, Trivellin G, Colli LM, Takiya CM, Stiles CE, Barry S, de Castro M, Gadelha MR, Korbonits M: Regulation of aryl hydrocarbon receptor interacting protein (AIP) protein expression by MiR-34a in sporadic somatotropinomas. PloS One 10: e0117107, 2015

11. Ehrlich L, Hall C, Venter J, Dostal D, Bernuzzi F, Invernizzi $P$, Meng F, Trzeciakowski JP, Zhou T, Standeford H, Alpini G, Lairmore TC, Glaser S: miR-24 inhibition increases menin expression and decreases cholangiocarcinoma proliferation. Am J Pathol 187:570-580, 2017

12. El-Assal ON, Yamanoi A, Ono T, Kohno H, Nagasue N: The clinicopathological significance of heparanase and basic fibroblast growth factor expressions in hepatocellular carcinoma. Clin Cancer Res 7:1299-1305, 2001

13. Feng R, Chen X, Yu Y, Su L, Yu B, Li J, Cai Q, Yan M, Liu B, Zhu Z: miR-126 functions as a tumour suppressor in human gastric cancer. Cancer Lett 298: 50-63, 2010

14. Fukui S, Otani N, Nawashiro H, Yano A, Nomura N, Miyazawa T, Ohnuki A, Tsuzuki N, Katoh H, Ishihara S, Shima K: Subcellular localization of basic fibroblast growth factor and fibroblast growth factor receptor 1 in pituitary adenomas. Brain Tumor Pathol 19:23-29, 2002

15. Huang W, Lin J, Zhang H: miR-126: A novel regulator in colon cancer. Biomed Rep 4:131-134, 2016

16. Jia W, Lu R, Jia G, Ni M, Xu Z: Expression of pituitary tumor transforming gene (PTTG) in human pituitary macroadenomas. Tumour Biol 34: 1559-1567, 2013

17. Knosp E, Steiner E, Kitz K, Matula C: Pituitary adenomas with invasion of the cavernous sinus space: A magnetic resonance imaging classification compared with surgical findings. Neurosurgery 33: 610-617; discussion 617-618, 1993

18. Kumar B, Yadav A, Lang J, Teknos TN, Kumar P: Dysregulation of microRNA-34a expression in head and neck squamous cell carcinoma promotes tumor growth and tumor angiogenesis. PLoS One 7:e37601, 2012
19. Lewis BP, Burge CB, Bartel DP: Conserved seed pairing, often flanked by adenosines, indicates that thousands of human genes are microRNA targets. Cell 120:15-20, 2005

20. Li Q, Wang N, Wei H, Li C, Wu J, Yang G: miR-24-3p regulates progression of gastric mucosal lesions and suppresses proliferation and invasiveness of N87 via peroxiredoxin 6. Dig Dis Sci 61:3486-3497, 2016

21. Li Y, Zhou LP, Ma P, Sui CG, Meng FD, Tian X, Fu LY, Jiang YH: Relationship of PTTG expression with tumor invasiveness and microvessel density of pituitary adenomas: A meta-analysis. Genet Test Mol Biomarkers 18:279-285, 2014

22. Li Z, Chen J: In vitro functional study of miR-126 in leukemia. Methods Mol Biol 676: 185-195, 2011

23. Mao ZG, He DS, Zhou J, Yao B, Xiao WW, Chen CH, Zhu $\mathrm{YH}$, Wang HJ: Differential expression of microRNAs in $\mathrm{GH}-$ secreting pituitary adenomas. Diagn Pathol 5: 79, 2010

24. Meij BP, Lopes MB, Ellegala DB, Alden TD, Laws ER Jr: The long-term significance of microscopic dural invasion in 354 patients with pituitary adenomas treated with transsphenoidal surgery. J Neurosurg 96:195-208, 2002

25. Mikami S, Ohashi K, Katsube K, Nemoto T, Nakajima M, Okada Y: Coexpression of heparanase, basic fibroblast growth factor and vascular endothelial growth factor in human esophageal carcinomas. Pathol Int 54:556-563, 2004

26. Pfaffl MW: A new mathematical model for relative quantification in real-time RT-PCR. Nucleic Acids Res 29: e45, 2001

27. Raverot G, Wierinckx A, Dantony E, Auger C, Chapas G, Villeneuve L, Brue T, Figarella-Branger D, Roy P, Jouanneau E, Jan M, Lachuer J, Trouillas J; HYPOPRONOS: Prognostic factors in prolactin pituitary tumors: Clinical, histological, and molecular data from a series of 94 patients with a long postoperative follow-up. J Clin Endocrinol Metab 95:17081716, 2010

28. Salehi F, Kovacs K, Scheithauer BW, Lloyd RV, Cusimano M: Pituitary tumor-transforming gene in endocrine and other neoplasms: A review and update. Endocr Relat Cancer 15: 721-743, 2008

29. Schroeder A, Mueller O, Stocker S, Salowsky R, Leiber M, Gassmann M, Lightfoot S, Menzel W, Granzow M, Ragg T: The RIN: An RNA integrity number for assigning integrity values to RNA measurements. BMC Mol Biol 7:3, 2006

30. Shi H, Lin B, Huang Y, Wu J, Zhang H, Lin C, Wang Z, Zhu J, Zhao Y, Fu X, Lou Z, Li X, Xiao J: Basic fibroblast growth factor promotes melanocyte migration via activating PI3K/Akt-Rac1FAK-JNK and ERK signaling pathways. IUBMB Life 68:735747,2016

31. Sivapragasam M, Rotondo F, Lloyd RV, Scheithauer BW, Cusimano M, Syro LV, Kovacs K: MicroRNAs in the human pituitary. Endocr Pathol 22:134-143, 2011

32. Stone RL, Baggerly KA, Armaiz-Pena GN, Kang Y, Sanguino AM, Thanapprapasr D, Dalton HJ, Bottsford-Miller J, Zand B, Akbani R, Diao L, Nick AM, DeGeest K, Lopez-Berestein G, Coleman RL, Lutgendorf S, Sood AK: Focal adhesion kinase: An alternative focus for anti-angiogenesis therapy in ovarian cancer. Cancer Biol Ther 15: 919-929, 2014 
33. Sun B, Xu H, Zhang G, Zhu Y, Sun H, Hou G: Basic fibroblast growth factor upregulates survivin expression in hepatocellular carcinoma cells via a protein kinase B-dependent pathway. Oncol Rep 30: 385-390, 2013

34. Vlachos IS, Paraskevopoulou MD, Karagkouni D, Georgakilas G, Vergoulis T, Kanellos I, Anastasopoulos IL, Maniou S, Karathanou K, Kalfakakou D, Fevgas A, Dalamagas T, Hatzigeorgiou AG: DIANA-TarBase v7.0: Indexing more than half a million experimentally supported miRNA: mRNA interactions. Nucleic Acids Res 43: D153-D159, 2015

35. Waligorska-Stachura J, Andrusiewicz M, Sawicka-Gutaj N, Kubiczak M, Jankowska A, Liebert W, Czarnywojtek A, Wasko $\mathrm{R}$, Blanco-Gangoo AR, Ruchala M: Evaluation of survivin splice variants in pituitary tumors. Pituitary 18: 410-416, 2015

36. Wang F, Shu K, Lei T, Xue D: The expression of integrinbeta1 and FAK in pituitary adenomas and their correlation with invasiveness. J Huazhong Univ Sci Technolog Med Sci 28: 572-575, 2008

37. Wang $P$, Zhen $H$, Zhang J, Zhang $W$, Zhang $R$, Cheng $X$, Guo G, Mao X, Wang J, Zhang X: Survivin promotes glioma angiogenesis through vascular endothelial growth factor and basic fibroblast growth factor in vitro and in vivo. Mol Carcinog 51: 586-595, 2012

38. Wu ZB, Li WQ, Lin SJ, Wang CD, Cai L, Lu JL, Chen YX, Su ZP, Shang HB, Yang WL, Zhao WG: MicroRNA expression profile of bromocriptine-resistant prolactinomas. Mol Cell Endocrinol 395: 10-18, 2014
39. Yang IP, Tsai HL, Hou MF, Chen KC, Tsai PC, Huang SW, Chou WW, Wang JY, Juo SHH: MicroRNA-93 inhibits tumor growth and early relapse of human colorectal cancer by affecting genes involved in the cell cycle. Carcinogenesis 33: 15221530, 2012

40. Yang $X$, Wu H, Ling T: Suppressive effect of microRNA-126 on oral squamous cell carcinoma in vitro. Mol Med Rep 10: 125130, 2014

41. Yang Z, Wang R, Zhang T, Dong X: MicroRNA-126 regulates migration and invasion of gastric cancer by targeting CADM1. Int J Clin Exp Pathol 8: 8869-8880, 2015

42. Yu G, Jia Z, Dou Z: miR-24-3p regulates bladder cancer cell proliferation, migration, invasion and autophagy by targeting DEDD. Oncol Rep 37: 1123-1131, 2017

43. Zhang D, Zhou J, Dong M: Dysregulation of microRNA-34a expression in colorectal cancer inhibits the phosphorylation of FAK Via VEGF. Dig Dis Sci 59: 958-967, 2014

44. Zhang MX, Zhang J, Zhang H, Tang H: miR-24-3p suppresses malignant behavior of lacrimal adenoid cystic carcinoma by targeting $\mathrm{PRKCH}$ to regulate $\mathrm{p53/p21}$ pathway. PLoS One 11: e0158433, 2016

45. Zhang W, Chu YQ, Ye ZY, Zhao ZS, Tao HQ: Expression of hepatocyte growth factor and basic fibroblast growth factor as prognostic indicators in gastric cancer. Anatomical record (Hoboken, NJ : 2007) 292: 1114-1121, 2009

46. Zhao P, Hu W, Wang H, Yu S, Li C, Bai J, Gui S, Zhang Y: Identification of differentially expressed genes in pituitary adenomas by integrating analysis of microarray data. Int $J$ Endocrinol 2015:164087, 2015 